\title{
Cervical corpectomy for resection of ventral intramedullary capillary hemangioma with circumferential involvement of the anterior spinal artery: case report
}

\author{
Jonathan A. Forbes, MD, ${ }^{1}$ Nathan Teschan, DO, ${ }^{2}$ Samuel Hayden Jones, BS, ${ }^{3}$ Phillip Parry, MD, ${ }^{1}$ \\ Luke Simonet, MD, ${ }^{4}$ and Narayana K. Swamy, MD ${ }^{1}$
}

Departments of ${ }^{1}$ Neurological Surgery and ${ }^{2}$ Pathology, David Grant Medical Center, Travis AFB; ${ }^{4}$ Department of Radiology, UC Davis Medical Center, Sacramento, California; and ${ }^{3}$ Weill Cornell Medical School, New York, New York

\begin{abstract}
There is limited evidence to suggest that anterior approaches for the resection of ventral intramedullary lesions of the cervical spinal cord may result in superior neurological outcomes compared with those following more traditional posterior approaches. To the authors' knowledge, no report of an anterior approach to resect a ventral intramedullary capillary hemangioma exists in the literature. In the following paper, the case of a 75-year-old male who presented with progressive neck and left shoulder pain, weakness of the left hand, myelopathy, and gait imbalance is reported. Postcontrast T1-weighted MRI demonstrated a homogeneously enhancing intramedullary lesion with associated severe impingement of the cervical spinal cord at C-4. Following a C-4 corpectomy, intradural exposure revealed a vascular lesion that circumferentially enveloped the anterior spinal artery. Gross-total resection of the lesion was performed, followed by reconstruction of the corpectomy defect, without neurological deterioration. Pathology was consistent with capillary hemangioma. In this instance, the anterior approach helped to avoid unnecessary neural manipulation and allowed for early identification of normal proximal and distal segments of the anterior spinal artery, which facilitated safe dissection and gross-total removal.
\end{abstract}

https://thejns.org/doi/abs/10.3171/2017.11.SPINE17868

KEYWORDS corpectomy; ventral; cervical; intramedullary capillary hemangioma; anterior spinal artery; vascular disorders

$\mathrm{V}$ ENTRAL cervical intramedullary (IM) lesions can be accessed via anterior or posterior surgical approaches. ${ }^{8,22,25}$ However, there is limited evidence to suggest that anterior approaches for resection may be associated with improved neurological outcomes when the lesion in question is located ventral to the dentate ligament. ${ }^{22}$ Only two surgical reports involving cervical IM capillary hemangiomas exist in the literature. ${ }^{12,25}$ In both of these cases, posterior surgical approaches were employed.

We report the case of a 75-year-old male who presented with progressive myeloradiculopathy and was found to have a ventral cervical IM lesion associated with severe neurological impingement and increased T2 signal involving the adjacent cervical spinal cord. The patient was taken for a C-4 corpectomy for intradural (ID) resection, which was performed without complication. To our knowledge, this is the first known description of an anterior approach for resection of an IM capillary hemangioma.

\section{Case Report}

History and Presentation

A 75-year-old male with a remote history of deep vein thrombosis on Coumadin presented with 6 months of progressive gait imbalance and 10/10 neck pain that radiated to his proximal left upper extremity. More recently, he had noted the new onset of sensory dysfunction involving his bilateral upper extremities (left $>$ right) and weakness of his left hand. Examination was notable for $3+$ hyperreflexia involving his brachioradialis, bicipital, triceps, patellar, and Achilles reflex on the left and mild (4+/5) weakness of left hand intrinsic muscles. Postcontrast T1-weighted MRI 
demonstrated a homogeneously enhancing IM lesion with associated severe impingement of the cervical spinal cord at C-4 (Fig. 1). T2-weighted imaging demonstrated pathological increased T2 signal involving the entirety of the cervical cord.

Based on appearance on MRI, the neuroradiology team initially believed the lesion to be most consistent with hemangioblastoma-although other histopathologies were included in the differential diagnosis. In the context of the patient's long-standing history of smoking, CT studies of the chest, abdomen, and pelvis were obtained; no other suspicious foci were identified. Given the unusual radiological appearance, as well as the prevailing sentiment that the lesion's size was out of proportion to the neurological deficit, neurology was consulted. Lumbar puncture was subsequently performed: cytology was negative and CSF analysis was unremarkable. Surgical and conservative management strategies were discussed. In the setting of considerable pain and progressive neurological decline, the patient elected to proceed with surgery. Given the ventral location of the lesion and suspected intimate involvement with the anterior spinal artery, an anterior approach was chosen.

\section{Surgery}

Following intubation, an arterial line was placed, followed by lumbar drain insertion. Somatosensory and motor-evoked potentials monitoring was instituted. A localizing radiograph was used to plan a transverse incision. Following dissection and repeat radiographic localization, discectomies were performed at $\mathrm{C} 3-4$ and $\mathrm{C} 4-5$ prior to the completion of a wide C-4 corpectomy. Epidural hemostasis was attained, and the operating microscope was subsequently brought into the field. The dura mater was initially opened in a linear manner in line with the axis of the spine. A large varix could be appreciated deep to the dural opening (Fig. 2A). The lateral margin between lesion and cord was not initially visible. A second transverse incision was then used to open the dura in a cruciate manner-this provided an excellent view of the lateral interface between lesion and cord. Dural tack-up stitches were placed. A small exophytic component was visible superficially. Upon further inspection, we found this component to transition to an IM component deep. The anterior spinal artery was enveloped by the lesion but could be visualized at the rostral and caudal extent of the exposure.

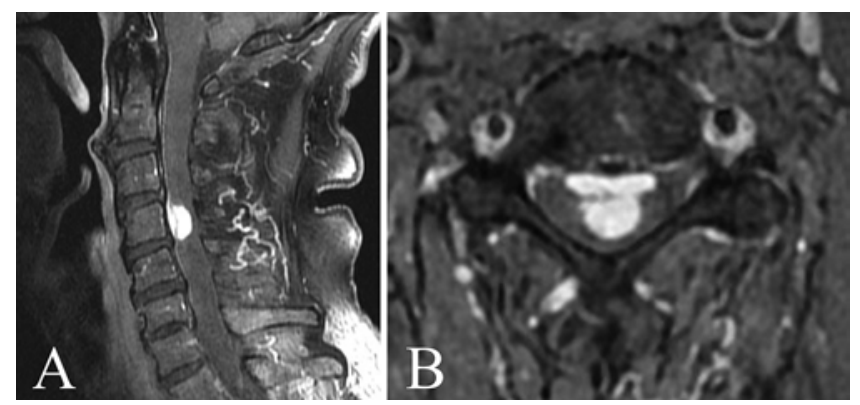

FIG. 1. Sagittal (A) and axial (B) postcontrast fat-saturated T1-weighted MR images demonstrate a homogeneously enhancing ID neoplasm with a large IM component posterior to the $\mathrm{C}$-4 vertebral body.
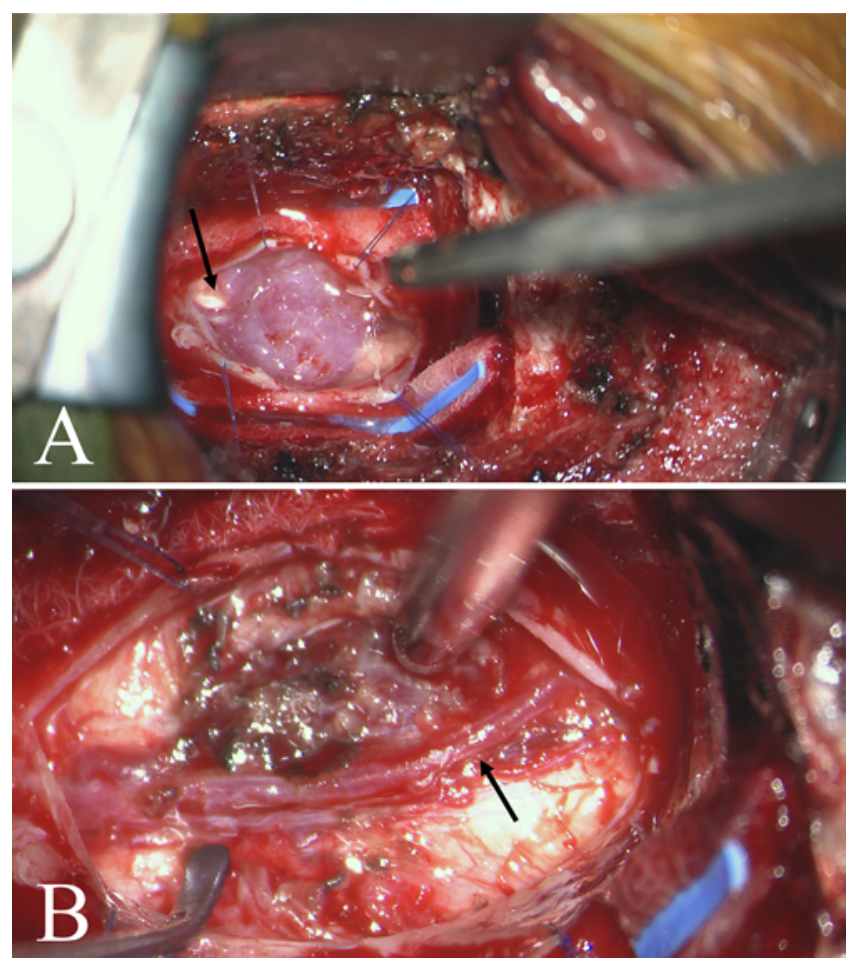

FIG. 2. A: Following a cruciate dural opening, a varix could be identified superficially. Arrow designates anterior spinal artery visible rostrally. B: Following removal of the superficial extramedullary component, a large IM component could be visualized deep to the anterior spinal artery (arrow). Figure is available in color online only.

The arachnoid was sharply dissected around the superficial varix-which was disconnected from the deep extension and sharply dissected off the anterior spinal artery. An additional larger IM component was visible deep to the anterior spinal artery (Fig. 2B). The interface between normal pia and lesion here was noted to exhibit significant vascularity. We coagulated and sharply transected small feeding pial vessels and circumferentially dissected this interface. This allowed access to a well-defined plane in between tumor and normal spinal cord. The margins were circumferentially dissected, and the deep component of the lesion was removed. Hemostasis was obtained. The dura was closed using interrupted 6-0 Prolene sutures and a Durepair (Medtronic) dural graft. Tisseel (Baxter International Inc.) was placed overlying the graft at the margin of the dural closure. A Globus Fortify titanium expandable cage was packed with autograft, introduced into the corpectomy defect, and expanded to reconstruct the anterior column. A C3-5 anterior spinal fusion was accomplished using a $34-\mathrm{mm}$ plate and four $4.2 \times 16-\mathrm{mm}$ screws. A Jackson-Pratt (JP) drain was left prior to closing the wound in the standard fashion.

\section{Postoperative Course}

Postoperatively, anteroposterior and lateral plain radiographs of the construct were obtained (Fig. 3). The JP drain remained in place for 24 hours postoperatively. The lumbar drain output was maintained at $10 \mathrm{ml} / \mathrm{hr}$ prior to discontinuation on the morning of postoperative day 


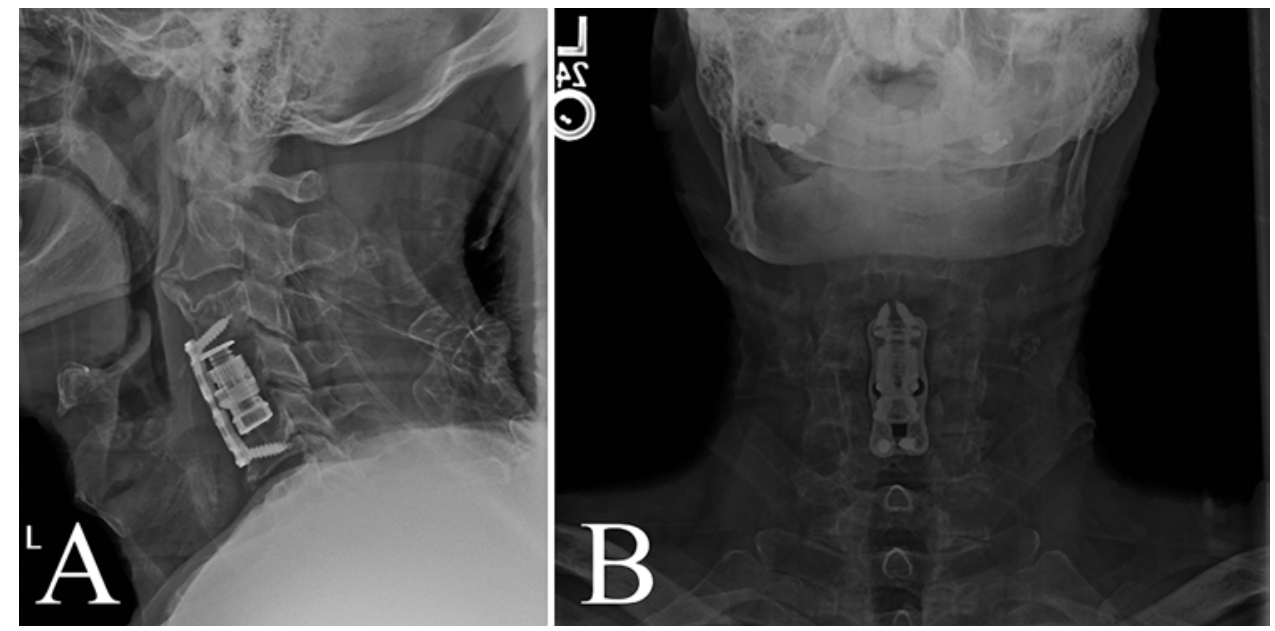

FIG. 3. Postoperative lateral (A) and anteroposterior (B) radiographs obtained following C-4 corpectomy for resection of a ventral IM capillary hemangioma demonstrate titanium expandable cage placement with C3-5 anterior instrumentation.

3. The patient's neurological examination and ability to ambulate remained unchanged following surgery. He was mobilized with physical therapy and cleared for discharge home on postoperative day 5 .

Pathological sections from the operative specimen showed vascular proliferation consisting of thin-walled vessels (Fig. 4). No atypia or increased mitotic activity was identified. Immunohistochemical staining showed the lesional tissue was positive for CD31, CD34, and ERG. The tissue was negative for inhibin, keratin (AE1/AE3), epithelial membrane antigen, and S100. Following glial fibrillary acidic protein (GFAP) staining, there was no evidence of intervening glial tissue. A final diagnosis of capillary hemangioma was rendered at this time.

Routine MRI was performed in the early postoperative period. In comparison with preoperative imaging (Fig. 5A), this early study confirmed gross-total resection of the capillary hemangioma-although residual T2 hyperintense signal involving the substance of the cervical spinal cord was effectively unchanged (Fig. 5B). Two weeks following surgery, the patient returned to clinic. At this visit, he reported full recovery of strength in his left hand as well as resolution of the preoperative radicular pain. He was noted to be neurologically intact on examination and denied any element of swallowing dysfunction. Repeat MRI performed approximately 1 year following surgery (Fig. 5C) continued to demonstrate no evidence of residual hemangioma. This study was also notable in that it demonstrated full resolution of the abnormal T2hyperintense cord signal that had been present on images obtained prior to and immediately following surgery. The patient reported no residual discomfort at this visit. Plain radiographs showed stable and appropriate placement of hardware with early radiological evidence of successful arthrodesis across the instrumented levels.

\section{Discussion}

Approximately 6\% of all spinal ID lesions are related to vascular etiologies ${ }^{6,14,20,23}$ Cavernous angiomas, in particular, account for 5\%-12\% of vascular lesions of the spine.
In contradistinction to cavernous angiomas, ID capillary hemangiomas are relatively infrequent. The occurrence of an IM capillary hemangioma, in particular, is considered an exceedingly rare phenomenon. ${ }^{6,714,21}$ To illustrate this point, a recent meta-analysis identified 632 reported cases of IM cavernous malformations. ${ }^{4}$ On the contrary, fewer than 20 cases of IM capillary hemangiomas have been reported. $3,5,10,12,18,24,25$

The distinction between cavernous and capillary hemangiomas is based on associated microscopic characteristics, including dominant vessel size. ${ }^{12}$ Capillary hemangiomas are composed of a lobular architecture with numerous small vessels separated by fibrous septae, whereas cavernous hemangiomas exhibit a preponderance of large, dilated vascular channels without septae. ${ }^{914}$ Previous reports have indicated that clinical deterioration referable to IM capillary hemangioma is often insidious and related to progressive hypertrophic growth, whereas IM cavernous angiomas may be more prone to exhibit abrupt neurological deterioration secondary to hemorrhage. ${ }^{21}$ Given the rarity of IM capillary hemangiomas, it is not surprising that they are commonly excluded from the differential di-

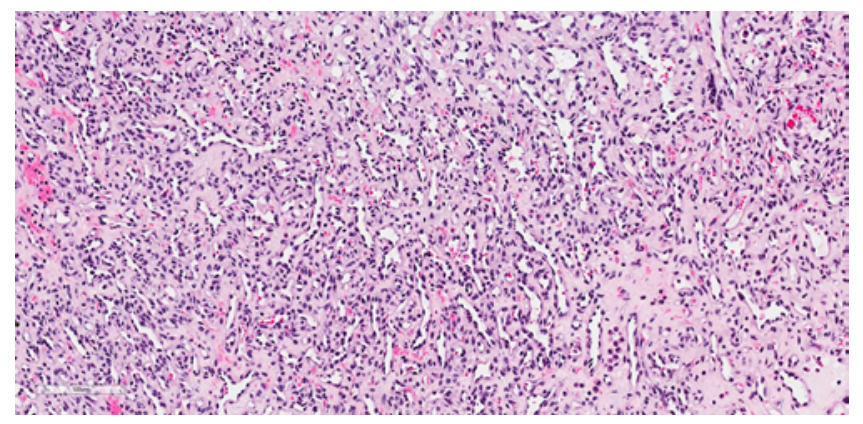

FIG. 4. Photomicrograph demonstrating findings typical of capillary hemangioma: numerous irregular thin-walled capillary-sized vessels without endothelial atypia. Vessels are arranged close to a circumscribed lobular architecture. Scattered extramedullary hematopoiesis is present. $H \& E$, original magnification $\times 40$. Figure is available in color online only. 


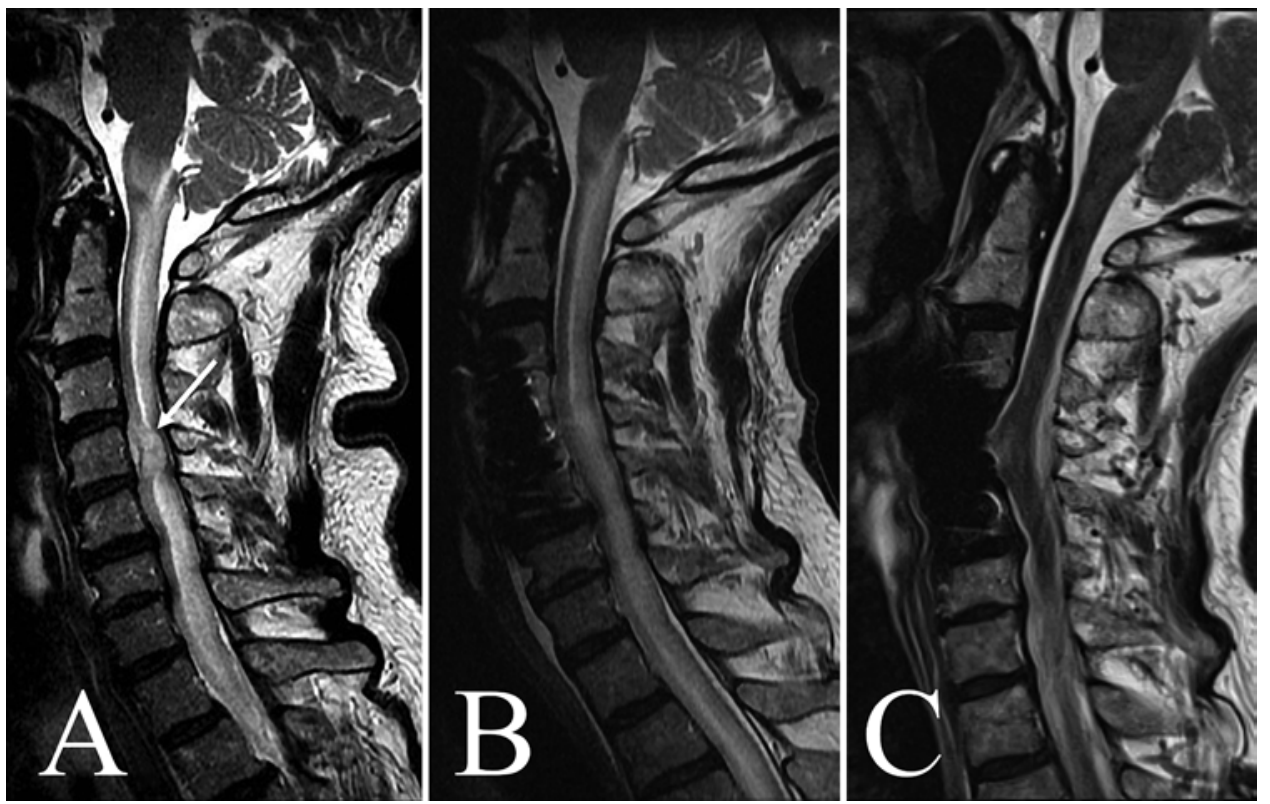

FIG. 5. A: Preoperative sagittal T2-weighted MR image demonstrates a ventral IM lesion posterior to the C-4 vertebral body with a marked increase in T2 signal involving the cervical cord. Arrow indicates the interface between tumor and normal cord. B: Sagittal T2-weighted image obtained in the immediate postoperative period, demonstrating gross-total resection of the lesion with persistent T2-hyperintense cord signal abnormality (artifact from titanium hardware present anteriorly). C: Sagittal T2-weighted image obtained approximately 1 year following surgery continues to demonstrate gross-total resection of the lesion with interval full resolution of the T2-hyperintense cord signal abnormality.

agnosis of IM lesions, as with the case described above..$^{25}$ The hallmark radiological feature of IM capillary hemangiomas is uniform enhancement on T1-weighted postcontrast imaging. ${ }^{21,25}$ Precontrast lesion T1 isointensity and T2 hyperintensity, as well as associated syringomyelia of the spinal cord, are present in the majority of cases. As with the patient described in this report, relatively large IM capillary hemangiomas can present with minimal associated neurological deficit. The most frequent clinical complaint at the time of presentation is pain; unlike with gliomas, symptoms are often present more than 6 months prior to initial evaluation..$^{25}$

Owing in part to the rarity of these lesions, the optimal surgical approach for resection of ventral cervical IM capillary hemangiomas is unknown. ${ }^{12,25}$ Alternative reports describing more common ventral IM lesions provide some element of guidance. Labauge et al. noted a correlation between ventral location of IM cavernous hemangiomas and poorer neurological outcomes following surgical intervention. ${ }^{17}$ In light of this associated increased surgical morbidity, a higher threshold for surgery in patients with ventral IM cavernous hemangiomas has been advocated. ${ }^{11}$ When surgery is recommended for ventral cervical IM lesions, perhaps the most important decision is whether to use an anterior or a posterior approach for resection. This very question was investigated by Pluta et al. in a series of 8 patients with ventral IM cervical or thoracic hemangioblastomas. ${ }^{22}$ Although limited by the small number of patients involved, the retrospective nature, and the inclusion of patients with thoracic tumors-for which an anterior approach was not considered-this study reported a clear benefit in both the short- and long-term ability to am- bulate in patients with ventral tumors whose surgery was conducted via an anterior approach. Despite a potential advantage in postoperative neurological function, the anterior approach is associated with drawbacks as well. The surgical field is deep, and lateral access can be limited. Ventral ID work is unfamiliar to many neurosurgeons and is associated with a significant risk of postoperative CSF fistula. ${ }^{2}$ Additionally, when the operative view requires corpectomy, reconstruction and stabilization are necessary. With these factors in mind, it is not surprising that some authors who favor the anterior approach for resection of small ventral hemangioblastomas have cautioned against using this strategy for larger tumors..$^{13}$

There are two reports of cervical IM capillary hemangiomas treated with surgical intervention in the literature (Table 1). These descriptions, while relevant to this discussion, provide little in the way of surgical guidance. In the report by Hida et al., a posterior approach for biopsy alone was chosen for a large capillary hemangioma that was associated with progressive neurological decline and an edematous underlying cord..$^{12}$ This procedure was complicated by a transient slight neurological deterioration. (Of note, the histopathological diagnosis of capillary hemangioma rendered in this case has subsequently been called into question by Nowak and Widenka. ${ }^{21}$ ) In a separate description, Wu et al. reported a posterior approach for resection of a small, slightly dorsal C7-T1 cervical IM capillary hemangioma that was also associated with a transient neurological deterioration. ${ }^{25}$ In contrast to the IM variety, surgical experience with ID extramedullary capillary hemangiomas is more robust. Given the considerable vascularity associated with capillary hemangiomas that 
TABLE 1. Summary of studies on patients who required surgery for ventral IM hemangioma of the cervical spinal cord

\begin{tabular}{lccccccr}
\hline Authors \& Year & $\begin{array}{c}\text { Age (yrs)/ } \\
\text { Sex }\end{array}$ & Levels Involved & Presentation & Surgical Plan & Approach & Degree of Resection & Complications \\
\hline Hida et al., 1993* & 50/M & C3-T1 & Tetraparesis & Biopsy & Posterior & N/A & $\begin{array}{c}\text { Transient neurologi- } \\
\text { cal deterioration }\end{array}$ \\
\hline Wu et al., 2013 & 47/M & C7-T1 & $\begin{array}{c}\text { Right lower extremity numb- } \\
\text { ness \& weakness }\end{array}$ & Resection & Posterior & $\begin{array}{c}\text { GTR } \\
\text { Transient neurologi- } \\
\text { cal deterioration }\end{array}$ \\
\hline Present case & $75 / M$ & C-4 & $\begin{array}{c}\text { Neck/left shoulder pain, } \\
\text { gait ataxia, \& left hand } \\
\text { weakness }\end{array}$ & Resection & Anterior & GTR & None \\
\hline
\end{tabular}

GTR = gross-total resection; N/A = not applicable.

* Histopathological diagnosis of capillary hemangioma has been called into question by Nowak and Widenka, 2001.

has been reported in this setting, many authors have recommended en bloc resection to minimize intraoperative hemorrhage, which can hamper attempts at gross-total resection. ${ }^{1,15,16,21}$

In light of the rarity of ventral ID surgery, the surgical nuances of our case merit additional discussion. Despite a wide corpectomy, given the large axial presentation of the lesion described, we found it necessary to open the dura in a cruciate manner to allow full visualization of the lateral margin of the lesion and normal spinal cord. While this maneuver made subsequent reconstruction of the dural layer more difficult and likely increased the risk of postoperative CSF fistula, we believe it optimized safe dissection of the perimeter of the lesion, which in turn facilitated early identification of the anterior spinal artery. Additionally, in this case we chose to mobilize and subsequently resect the smaller exophytic component of the lesion prior to dissection of the larger IM component. While this goes against the traditional surgical dogma of capillary hemangiomas discussed above, we found that removal of the exophytic component allowed for full visualization of the anterior spinal artery (Fig. 2B) prior to dissection of the deep component. Interestingly, resection of the exophytic component was associated with minimal bleeding. Instead, considerable vascularity was encountered during sharp dissection of the deep component of the lesion from the adjacent pial interface. Because electrophysiological activity did not deteriorate during surgery, topical papaverine-soaked Gelfoam was not applied-although the prophylactic use of this agent to safeguard against vasospasm of the anterior spinal artery would have been a reasonable consideration. Given the increased risk of postoperative CSF fistula in the setting of the aforementioned ventral approach, we chose to buttress the dural closure with fibrin glue and maintain continuous lumbar drainage for 72 hours postoperatively.

This report supports previous assertions that a ventral location of an IM cervical lesion can be safely addressed from an anterior vantage..$^{13,19,22}$ Benefits of the anterior approach in this setting include early visualization of the anterior spinal artery and the avoidance of neural manipulation associated with posterior approaches. Drawbacks include a deep and somewhat unfamiliar ID surgical corridor, an increased risk of postoperative CSF fistula, and the subsequent need for anterior column reconstruction. It is important to note that both anterior and posterior approaches remain valid options in the surgical treatment of lesions similar to the one described in this report. The choice of surgical approach will be influenced by individual characteristics of the patient and tumor and ultimately guided by the experience and discretion of the treating neurosurgeon. While information gained from a single case report is undoubtedly limited, it is our hope that the principles described above may prove beneficial to other neurosurgeons confronted with similar pathology.

\section{Conclusions}

This case report describes an anterior approach for resection of a ventral IM capillary hemangioma of the cervical spinal cord found to circumferentially involve the anterior spinal artery. Intraoperative photographs and a discussion of surgical nuances of the ventral ID approach are provided. To our knowledge, this report represents the first known description of a ventral approach for resection of an IM capillary hemangioma.

\section{Acknowledgments}

We thank Kai Hoffman for his assistance with all aspects of instrumentation.

\section{References}

1. Andaluz N, Balko MG, Stanek J, Morgan C, Schwetschenau PR: Lobular capillary hemangioma of the spinal cord: case report and review of the literature. J Neurooncol 56:261264, 2002

2. Angevine PD, Kellner C, Haque RM, McCormick PC: Surgical management of ventral intradural spinal lesions. J Neurosurg Spine 15:28-37, 2011

3. Babu R, Owens TR, Karikari IO, Moreno J, Cummings TJ, Gottfried ON, et al: Spinal cavernous and capillary hemangiomas in adults. Spine (Phila Pa 1976) 38:E423-E430, 2013

4. Badhiwala JH, Farrokhyar F, Alhazzani W, Yarascavitch B, Aref M, Algird A, et al: Surgical outcomes and natural history of intramedullary spinal cord cavernous malformations: a single-center series and meta-analysis of individual patient data. J Neurosurg Spine 21:662-676, 2014

5. Chung SK, Nam TK, Park SW, Hwang SN: Capillary hemangioma of the thoracic spinal cord. J Korean Neurosurg Soc 48:272-275, 2010

6. Cosgrove GR, Bertrand G, Fontaine S, Robitaille Y, Melanson D: Cavernous angiomas of the spinal cord. J Neurosurg 68:31-36, 1988

7. Deutsch H, Jallo GI, Faktorovich A, Epstein F: Spinal in- 
tramedullary cavernoma: clinical presentation and surgical outcome. J Neurosurg 93 (1 Suppl):65-70, 2000

8. Eicker SO, Szelényi A, Mathys C, Steiger HJ, Hänggi D: Custom-tailored minimally invasive partial C2-corpectomy for ventrally located intramedullary cavernous malformation. Neurosurg Rev 36:487-491, 2013 (Erratum in Neurosurg Rev 36:493, 2013)

9. Enzinger FM, Weiss SW: Benign tumors and tumor-like lesions of blood vessels, in Enzinger FM, Weiss SH (eds): Soft Tissue Tumors, ed 3. St. Louis: Mosby, 1995, pp 581-586

10. Gonzalez R, Spears J, Bharatha A, Munoz DG: Spinal lobular capillary hemangioma with an intramedullary component. Clin Neuropathol 33:38-41, 2014

11. Gross BA, Du R, Popp AJ, Day AL: Intramedullary spinal cord cavernous malformations. Neurosurg Focus 29(3):E14, 2010

12. Hida K, Tada M, Iwasaki Y, Abe H: Intramedullary disseminated capillary hemangioma with localized spinal cord swelling: case report. Neurosurgery 33:1099-1101, 1993

13. Iwasaki Y, Koyanagi I, Hida K, Abe H: Anterior approach to intramedullary hemangioblastoma: case report. Neurosurgery 44:655-657, 1999

14. Jellinger K: Pathology of spinal vascular malformations and vascular tumors, in Pie HW, Djindjian R (eds): Spinal Angiomas: Advances in Diagnosis and Therapy. New York: Springer, 1978

15. Kasukurthi R, Ray WZ, Blackburn SL, Lusis EA, Santiago P: Intramedullary capillary hemangioma of the thoracic spine: case report and review of the literature. Rare Tumors 1:e10, 2009

16. Kelleher T, Aquilina K, Keohane C, O'Sullivan MG: Intramedullary capillary haemangioma. Br J Neurosurg 19:345348,2005

17. Labauge P, Bouly S, Parker F, Gallas S, Emery E, Loiseau H, et al: Outcome in 53 patients with spinal cord cavernomas. Surg Neurol 70:176-181, 2008

18. Melcher C, Wegener B, Niederhagen M, Jansson V, Birkenmaier $\mathrm{C}$ : An intramedullary capillary hemangioma of the spine with an underlying plasmocytoma. Spine J 13:e1-e4, 2013

19. Nishikawa M, Ohata K, Ishibashi K, Takami T, Goto T, Hara $\mathrm{M}$ : The anterolateral partial vertebrectomy approach for ven- trally located cervical intramedullary cavernous angiomas. Neurosurgery 59 (1 Suppl 1):ONS58-ONS63, 2006

20. Norstrom CW, Kernohan JW, Love JG: One hundred primary caudal tumors. JAMA 178:1071-1077, 1961

21. Nowak DA, Widenka DC: Spinal intradural capillary haemangioma: a review. Eur Spine J 10:464-472, 2001

22. Pluta RM, Iuliano B, DeVroom HL, Nguyen T, Oldfield EH: Comparison of anterior and posterior surgical approaches in the treatment of ventral spinal hemangioblastomas in patients with von Hippel-Lindau disease. J Neurosurg 98:117-124, 2003

23. Rasmussen TB, Kernohan JW, Adson AW: Pathologic classification, with surgical consideration, of intraspinal tumors. Ann Surg 111:513-530, 1940

24. Shen G, Su M, Zhao J, Liu B, Kuang A: Capillary hemangioma of thoracic spinal cord: PET/CT and MR findings. Clin Nucl Med 42:408-409, 2017

25. Wu L, Deng X, Yang C, Xu Y: Intramedullary spinal capillary hemangiomas: clinical features and surgical outcomes: clinical article. J Neurosurg Spine 19:477-484, 2013

\section{Disclosures}

The authors report no conflict of interest concerning the materials or methods used in this study or the findings specified in this paper.

\section{Author Contributions}

Conception and design: Forbes, Swamy. Acquisition of data: Forbes, Swamy. Analysis and interpretation of data: Forbes, Teschan, Simonet, Swamy. Drafting the article: Forbes, Teschan, Simonet. Critically revising the article: Forbes, Swamy. Reviewed submitted version of manuscript: Forbes, Simonet, Swamy. Approved the final version of the manuscript on behalf of all authors: Forbes. Administrative/technical/material support: Forbes, Jones, Parry, Swamy. Study supervision: Forbes.

\section{Correspondence}

Jonathan A. Forbes: David Grant Medical Center, Travis AFB, CA. jonathan.a.forbes@gmail.com. 